\title{
Mediaciones para un método de teología pastoral, a partir de la teología práctica de Karl Rahner
}

\author{
Alex Vigueras Cherres
}

\section{INTRODUCCIÓN}

Las reflexiones que presentamos a continuación forman parte de nuestra tesis doctoral: «En la meta hacia la meta: La perspectiva escatológica como horizonte de comprensión de la teología práctica en Karl Rahner» ${ }^{1}$, en la cual sostenemos que una correcta comprensión de su teología práctica supone ponerla en relación con la perspectiva escatológica que atraviesa el conjunto de su obra. A diferencia de la escatología (la ciencia teológica que tiene que ver con la doctrina de las cosas últimas, los éschata, aquello que comienza con la muerte y la trasciende), lo escatológico tiene que ver con una cualidad del presente en cuanto presente de salvación, cualidad que define no solo la vida de la Iglesia y los cristianos, sino de la humanidad y del mundo. Nosotros hemos caracterizado esa dimensión escatológica del presente con la formulación «en la meta, hacia la meta $»^{2}$. Desde una mirada creyente afirmamos que el mundo y la humanidad no son impulsados hacia el futuro por el puro autodespliegue de las posibilidades de la materia (como lo afirma el evolucionismo y el marxismo), sino por la fuerza del futuro absoluto, Dios, que se ha autocomunicado al ser humano y al mundo y ha llegado a ser su principio más íntimo. Por ello la humanidad y el mundo caminan en

\footnotetext{
1 A. Vigueras, En la meta hacia la meta: La perspectiva escatológica como horizonte de comprensión de la Teología Práctica en Karl Rahner. (FAJE, Belo Horizonte 2010). Parte de esta tesis doctoral ha sido publicada en la revista Teología y Vida: A. Vigueras, «Teología Práctica de Karl Rahner: Una teología pastoral en perspectiva escatológica». Teología y Vida 51 (2010) 445-476.

2 K. Rahner, Kirche und Parusie Christi (Sämtliche Werke 10; Herder, Freiburg 2003) 629.
} 
la meta, y esa cualidad del presente sostenido por la autocomunicación de Dios lo pone en tensión escatológica hacia el futuro absoluto en un dinamismo que nunca se agota y, por eso, la humanidad y el mundo caminan siempre hacia la meta.

En nuestra investigación afirmamos que la perspectiva escatológica es el horizonte de comprensión de la teología práctica en Rahner. La justificación de esta hipótesis implica afirmar que su teología práctica es una teología práctica en perspectiva escatológica. Si bien es cierto, toda ciencia debe ser siempre crítica, el fundamento de la criticidad de una teología no puede ser idéntico al de las otras ciencias humanas o exactas. Nosotros establecemos un vínculo entre criticidad propiamente teológica y perspectiva escatológica, lo cual nos parece relevante puesto que un problema en la historia de la teología práctica ha sido una excesiva asimilación a esas otras ciencias, que la ha llevado a perder su propia identidad, llegando al extremo de dejarse delimitar en sus posibilidades críticas por esas otras ciencias, sin buscar suficientemente, desde ella misma, esas posibilidades y límites.

Presentamos a continuación el que -según nuestro parecer- es el problema fundamental a la hora de pensar un método de la teología pastoral: el carácter teológico del análisis de la situación presente. Luego, en el tercer apartado, proponemos algunas mediaciones metodológicas (no solo para la teología pastoral, sino también para la acción pastoral) que pueden inferirse a partir de la concepción de teología práctica de Rahner.

2. El problema fundamental: El carácter teológico del anÁlisis DE LA SITUACIÓN PRESENTE

\subsection{El análisis científico-teológico de la situación presente}

Para Rahner la teología práctica es aquella ciencia teológica que «bajo el análisis científico y, precisamente, teológico de la situación concreta (...) en cada momento de la Iglesia, desarrolla los principios (y en la medida de lo posible los concreta en imperativos), según los cuales la Iglesia en esta determinada situación (es decir, en cada momento actual) actualiza su propia esencia y así realiza su actividad de salvación» ${ }^{3}$.

3 K. Rahner, Pastoraltheologie- ein Überblick (Sämtliche Werke 19; Herder, Freiburg 1995) 6-7. 
Para la tematización de su objeto específico, la teología práctica recurre al análisis científico-teológico de la situación presente. Tal análisis es necesario por varias razones: en primer lugar, porque la teología práctica no puede tomar un análisis de este tipo de alguna de las ciencias que versan sobre la esencia, pues ellas no tienen medios para llevarlo a cabo. En segundo lugar, para evitar que la teología práctica sea un mero recetario práctico para la praxis pastoral, sin capacidad de situarse críticamente frente a esta; y, en tercer lugar, para evitar un análisis de la situación sin seriedad científica ${ }^{4}$.

Es necesario no perder de vista que con su teología práctica Rahner intenta dar respuesta a una situación de crisis del cristianismo en el mundo moderno. Él percibe una vivencia cristiana sin pasión, desgastada y, parte de la explicación de esta situación, es el divorcio entre la vida de la Iglesia institucional y la vida de los individuos concretos. En la percepción de Rahner la Iglesia debe tomar conciencia de que no bastan los principios generales de la fe y la moral, pues, para que esos principios lleguen a tocar la vida concreta de los individuos, deben transformarse en imperativos concretos. El discernimiento de tales imperativos solo es posible a partir de una consideración de la situación presente, pues lo individual no solo es un caso de lo universal, sino algo irrepetiblemente único, que se da solo una vez. El análisis científico-teológico de la situación presente es el instrumento que propone para ello.

Rahner entiende la Iglesia como una magnitud histórica que no existe simplemente en una forma de concretización siempre igual. Ella debe acontecer en la historia de manera siempre nueva: «su evento no es simplemente la presencia duradera de su esencia en una temporalidad y espacialidad que permanece externa a ella, sino la forma histórica de su esencia, que se da solo una vez, y que está destinada para ella por el Espíritu de la Iglesia a través de su situación histórica que se da solo una vez» ${ }^{5}$. El hecho de ser la Iglesia de Cristo, sacramento de su victoria escatológica, no anula la tarea propia que ella tiene en la historia, la responsabilidad de su libertad, la capacidad de tomar decisiones y, por tanto, la posibilidad de cambio.

4 Cf. K. Rahner, Strukturwandel der Kirche als Chance und Aufgabe (Herder, Freiburg ${ }^{2}$ 1972) 21-22.

5 K. RaHner, Die praktische Theologie im Ganzen der theologischen Disziplinen (Sämtliche Werke 19; Herder, Freiburg 1995)505. 


\subsection{El carácter teológico del análisis de la situación presente}

En relación al análisis de la situación presente coincidimos con la percepción de Norbert Mette, quien señala que Rahner no llegó a formular con claridad la forma como se hace tal análisis, por lo cual urge la elaboración de un método. Un punto fundamental para él es preguntarse de dónde puede tomar la teología práctica la certeza de que ella encuentra una conciencia de la situación que concretamente es dada por el Espíritu y, por eso, puede ser caracterizada como carismática; ella no podría elaborar y formular una conciencia de su tiempo, ni de modo puramente intrateológico, ni de modo puramente intraeclesial, sino que necesita para eso de una especie de heterodeterminación cognitiva [Art kognitiver Fremdbestimmung $]^{6}$. Lo que está como telón de fondo es la pregunta por aquello que determina la teologicidad del análisis y cómo eso se relaciona con las ciencias auxiliares. Paul Zulehner responde a esta cuestión diciendo que existen en el análisis propuesto por Rahner dos niveles de reflexión: el primero es la aceptación crítica de todo el conocimiento adquirido de las ciencias humanas y, el segundo, la reflexión desde el punto de vista de Dios. Recién este segundo nivel sería propiamente una reflexión teológica ${ }^{7}$.

Para Mette no basta el recurso a las ciencias auxiliares, pues el análisis debe ser conducido de modo específicamente teológico. Hay que mirar el presente teológicamente, es decir, "con los ojos de la fe». Si se descompone la teología práctica en una parte analítico-crítica y otra normativa, habría que afirmar que el análisis de la situación no se sitúa solo del lado analítico-crítico, sino que influyen ya en él elementos normativos, pues tal análisis no puede ser ejecutado neutralmente ${ }^{8}$. No se trata solo de mirar un presente histórico, sino un kairós ${ }^{9}$. En ese sentido es pertinente

6 Cf. N. Mette, «Zwischen Reflexion und Entscheidung: Der Beitrag Karl Rahners zur Grundlegung der praktischen Theologie» en Trierer theologische Zeitschrift 87 (1978) 26-43.136-151, 151.

7 Cf. P.M. Zulehner, «La dimensione pastorale della teologia di Karl Rahner»en I. SANNA, L'eredità teológica di Karl Rahner (Lateran University, Roma 2005) 69-86, 75-76.

8 Cf. N. Mette, "Zwischen Reflexion und Entscheidung» 32.

9 En nuestro análisis genético (en la segunda parte de nuestra tesis doctoral [cf. nota 14]), constatamos que la conversio ad phantasma de Geist in Welt puede ser leída como conversio ad historiam en Hörer des Wortes; y, a partir de cómo Rahner entiende la lógica del conocimiento existencial de los Ejercicios [Cf.: K. Rahner, Die Logik 
la exhortación de R. Siebenrock: «Nosotros tenemos hoy que atrevernos, por propio riesgo, a emprender teología y no solo integrar siempre en nuestro trabajo nuevos métodos y resultados de otras ciencias para ensalzar a través de ello nuevos planteamientos. ¿En qué consiste, pues, lo teológico de la teología? No necesitamos tantos atributos o genitivos en la teología, sino simplemente más teología. ¡Tenemos que arriesgar más teología!» ${ }^{10}$.

Nosotros coincidimos más con Mette que con Zulehner, pues creemos que no se puede separar el análisis en dos niveles, como si el primero fuera preteológico y el segundo teológico. En efecto, creemos que, a partir de las intuiciones de Rahner, hay que afirmar que todo el proceso de la teología práctica debe ser teológico, descartando la posibilidad de un primer nivel de análisis preteológico.

\section{Posibles mediaciones metodológicas, a partir de las intuiciones DE RAHNER}

¿Qué significa el carácter teológico del análisis de la situación presente? ¿Qué elementos lo cualifican como específicamente teológico? Es lo que intentamos responder en la presentación de estas mediaciones.

\subsection{Mirar el futuro desde la "futuridad del presente" [Zukünftigkeit der Gegenwart]}

En el planteamiento sobre una nueva hermenéutica de las afirmaciones escatológicas ${ }^{11}$, Rahner rechaza un conocimiento del futuro a partir de una especie de reportaje desde el futuro, como si él se hubiese revelado con toda transparencia a algunos iluminados, y plantea que «el saber sobre lo futuro será el saber sobre la futuridad del presente, el saber escatológico es el saber sobre el presente escatológico» ${ }^{12}$. Por eso el ser humano solo sabe de ese futuro lo que de él puede experimentar prospectiva-

der existentiellen Erkenntnis bei Ignatius von Loyola (Sämtliche Werke 10; Herder, Freiburg 2003) 326-343], decimos que esa conversio ad historiam debe ser entendida como conversión al presente salvífico o, en otras palabras, conversión al kairós.

10 R. Siebenrock, "Theologie um der Seelsorge willen» en Diakonia 35 (2004) 369375,370 .

11 Cf. K. Rahner, Theologische Prinzipien der Hermeneutik eschatologischer Aussagen (Sämtliche Werke 12; Herder, Freiburg 2005) 489-510.

12 K. Rahner, Theologische Prinzipien der Hermeneutik eschatologischer Aussagen, 497. 
mente en su presente, desde y en su experiencia histórico-salvífica. Una teología práctica, en el análisis teológico de la situación presente, debiera considerar seriamente esta perspectiva hermenéutica si quiere que su mirada tenga verdaderamente una cualidad teológica. De aquí surge la pregunta por el modo como eso sea posible. Presentamos a continuación algunos caminos que podrían responder a esta necesidad.

\subsubsection{El dato revelado}

En la crítica que H. Schuster hace a Rahner se expresa como una carencia importante la falta de referencia que tendría su teología práctica al dato revelado, particularmente a Jesucristo. Para Schuster existe una carencia en la determinación del contenido de la autorrealización de la Iglesia, de un criterio para el ser y obrar debido de la Iglesia. A partir de esta carencia propone "la causa de Jesús» como criterio ${ }^{13}$. Pero, de hecho, en el análisis genético de nuestra investigación ${ }^{14}$ ha aparecido la necesaria referencia de la Iglesia al dato revelado, en particular al momento culminante de la autocomunicación de Dios: Jesucristo. Por ejemplo, cuando define la Iglesia como «la comunidad, societaria y legítimamente constituida, en la cual la revelación escatológicamente consumada de Dios en Cristo (como autocomunicación de Dios), a través de la fe, esperanza y amor, permanece presente para el mundo como realidad y verdad $»^{15}$, o cuando dice que el tiempo es finito, moldeable históricamente a partir de un origen auténtico y hacia un fin auténtico, que ya no es revisable, pues está dado de modo definitivo y, por eso, es un tiempo que transcurre ahora después de Cristo y, por ello, según Cristo [«nach» Christus $]^{16}$. A partir de ahí creemos que, si bien es cierto, esta temática está presente en la eclesiología rahneriana y en la teología práctica, ha faltado explicitar más la referencia de esta última a la revelación.

13 Cf. H. Schuster, «Die Praktische Theologie unter dem Anspruch der Sache Jesu» en F. Klostermann - R. Zerfaß (eds.)Praktische Theologie heute (Kaiser, München 1974) 150-163, 150-152.

14 Cf. A. Vigueras, En la meta hacia la meta, 45-167. Corresponde a toda la segunda parte de nuestra tesis.

15 K. Rahner, Ekklesiologische Grundlegung (Sämtliche Werke 19; Herder, Freiburg 1995) 49.

16 Cf. K. Rahner, Eschatologie, theol.- wissenschaftstheoretisch (Sämtliche Werke 17/1; Herder, Freiburg 2002) 220-225, 223-224. 
Si la teología práctica tiene que ver con una eclesiología «en el modo de la plenitud» [in den Modus der Vollendung $]^{17}$, entonces será relevante un criterio desde el cual discernir la voluntad de Dios para ella en una determinada situación histórica, para plasmarla en imperativos concretos. Ese criterio de futuro es un acontecimiento del pasado, no solo Cristo, sino toda la historia de la revelación consignada en las Sagradas Escrituras y que encuentra en Cristo su plenificación. El carácter verdaderamente futuro no queda anulado en esta referencia a un evento del pasado, pues aunque ya ha ocurrido en la historia es, sin embargo, un evento de potencialidad infinita por el que Dios mismo, futuro absoluto, se ha autocomunicado al ser humano y al mundo.

Por eso el acontecimiento de la revelación no es algo totalmente transparente para la Iglesia, como si la tarea ahora fuera solo transmitirlo a los otros que no lo conocen o no lo comprenden plenamente. Ese acontecimiento del pasado permanece misterio también para la Iglesia, conserva siempre un más que sobrepasa cualquier comprensión histórica. Por ello la Iglesia no solo es medio, sino también fruto de salvación, pues ella debe convertirse una y otra vez a partir de ese imperativo contenido en su evento originante.

En el discernimiento de los imperativos deben confluir el análisis de la situación presente y el criterio de la autorrealización: el dato revelado, pero no como si en la revelación ya estuviera clara la respuesta exigida por Dios a la Iglesia, sino que en una permanente interrelación mutua, inspiradora y crítica, entre el análisis de la situación presente y el horizonte bíblico. La teología práctica deberá, entonces, mantener una relación permanente no solo con las ciencias bíblicas, sino también con la pastoral bíblica de la Iglesia. Esta dimensión bíblica debería ser un elemento transversal que acompaña todo el proceso de la teología práctica, pues el dato revelado también puede iluminar un modo de análisis de la situación presente y un modo de llevar los imperativos a la praxis concreta.

\subsubsection{El ser humano singular}

Creemos que, desde la perspectiva de Rahner, el ser humano singular es un lugar teológico posible para una aproximación al futuro desde el presente escatológico. Esto ha quedado plasmado en el concepto indivi-

17 K. Rahner, Theologische Prinzipien der Hermeneutik eschatologischer Aussagen, 499. 
duum ineffabile, con el cual Rahner quiere expresar que "hay en el ser humano, igual que en el ángel, conciencia personal, libertad, historia irrepetible, responsabilidad absoluta y validez eterna de cada individuo ${ }^{18}$. Refiriéndose a la doctrina de santo Tomás sobre los ángeles señala que "cuando y en la medida que el ser humano como persona espiritual participa en sus actos de la subsistencia-en-sí-misma de la forma pura, que no desaparece en su ordenación a la materia como el principio de la repetibilidad, tiene él que participar de aquella individualidad espiritual de lo espiritual, que tiene una individualidad positiva ${ }^{19}$. Por ello el ser humano en cuanto individuo no es un mero caso de lo universal, pues «él es cada vez un [ser]-que-se-da-solo-una-vez y, en definitiva, nunca totalmente deducible» ${ }^{20}$ y, por ello, siempre futuro. Este concepto de individuum ineffabile se puede aplicar también a figuras individuales de orden superior: una comunidad determinada, un determinado tiempo de la Iglesia, un país determinado ${ }^{21}$. Esto no significa negar que exista una idea general del ser humano, una naturaleza general que le es propia, pues eso también es el ser humano ${ }^{22}$.

Ahora bien, en cuanto existe el individuum ineffabile «hay una llamada irreductible, individual de Dios a cada ser humano como individuo, que no puede ser considerada como la mera suma o el mero punto de cruce de los principios generales. Y esta llamada individual de Dios, no reducida a normas generales, «no es meramente el llamado a lo posible y a lo permitido al ser humano, por lo demás indiferente, sino al menos bajo condiciones, también absolutamente, llamada de Dios a lo que es significativo para la salvación y [a lo] imperativo» ${ }^{23}$. Es una llamada que se dirige al individuo concreto en una situación concreta, en su irrepetibilidad positiva, objetiva y material. A Dios le interesa la historia «en la medida que ella es una-única, y que, justamente por eso tiene un signifi-

18 K. Rahner, Der Anspruch Gottes und der Einzelne (Sämtliche Werke 10; Herder, Freiburg 2003) 469-480, 471.

19 K. Rahner, Über die Frage einer formalen Existentialethik (Sämtliche Werke 10; Herder, Freiburg 2003) 302-316, 309.d

20 K. Rahner, Würde und Freiheit des Menschen (Sämtliche Werke 10; Herder, Freiburg 2003) 184-206, 187.

21 Cf. K. Rahner, Der Anspruch Gottes und der Einzelne, 478.

22 Cf. K. Rahner, Der Anspruch Gottes und der Einzelne, 472.

23 K. Rahner, Der Anspruch Gottes und der Einzelne, 472. 
cado de eternidad ${ }^{24}$. El ser humano es individuo de este modo, porque es amado con un amor personalísimo de Dios que se le autocomunica. Por este amor, el más personal de todos [allerpersönlichste Liebe], el que es amado deviene un absolutamente único [eine absolute Einmaligkeit] ${ }^{25}$.

Pero esta individuación no lo separa de la realidad, pues cuanto mayor es la individualidad real y la plenitud del ser, tanto mayor será la proximidad y la vinculación con los demás seres. Esto se verifica en la experiencia humana del conocimiento y el amor, pues acontecen en el ser humano en una apertura a la realidad una que todo lo abraza. El sujeto espiritual, conociendo y amando, se abre a la realidad ilimitada y universal que llamamos $\operatorname{Dios}^{26}$. De este modo, afirmar que el ser humano, en cuanto individuo concreto, está destinado a la vida eterna, no tiene que ver solo con una condición que experimentará después de la muerte, sino con una cualidad del acto moral, pues los actos de un individuo no son mera modalidad espacio-temporal como lo material, sino que «tienen un significado de eternidad, no solo moralmente, sino también ontológicamente» ${ }^{27}$. El acto libre es un acto irreductible que configura para la eternidad; un acto que hace que cada uno sea lo que quiere ser definitivamente ${ }^{28}$, son «realizaciones de una individualidad personal-espiritual y sobrenatural-por-gracia en obediencia delante de un llamado totalmente personal y de una vocación realmente individual por parte de Dios» ${ }^{29}$. La realización de cada vocación individual tendrá una influencia decisiva en la salvación de los demás.

Así podemos afirmar que porque el ser humano es el evento de la autocomunicación gratuita de Dios, es un evento escatológico. Por esta razón el ser humano singular puede tornarse un lugar relevante para una teología práctica que quiere analizar teológicamente la situación pre-

24 K. Rahner, Über die Frage einer formalen Existentialethik, 311.

25 Cf. K. Rahner, Über die heilsgeschichtliche Bedeutung des einzelnen in der Kirche (Sämtliche Werke 10; Herder, Freiburg 2003) 421-446, 427-428.

26 Cf. K. Rahner, Über die heilsgeschichtliche Bedeutung des einzelnen in der Kirche, 423-424.

27 K. Rahner, Über die Frage einer formalen Existentialethik, 309. [Cursivas del autor].

28 Cf. K. Rahner, Die Freiheit in der Kirche (Sämtliche Werke 10; Herder, Freiburg 2003) 223.

29 K. Rahner, Über die heilsgeschichtliche Bedeutung des einzelnen in der Kirche, 428. 
sente. Nos parece que esto tiene que ver con el llamado que hace M. Schneider para una teología más fuertemente biográfica, fundada en la vida concreta y en la realización de la $\mathrm{fe}^{30}$. Si bien es cierto es un llamado que él hace a la teología en general, nos parece especialmente pertinente para la teología práctica.

A menudo los análisis de la realidad prestan más atención a lo global que a lo individual, a las inclinaciones de las mayorías que a las intuiciones individuales, lo cual puede coartar ese carácter único, ese más, esa dimensión inobjetivable de lo individual, podríamos decir, ese carácter siempre futuro del ser humano singular. Si, como Rahner señala, cada cristiano vive una experiencia de profetismo, a partir de su propia experiencia de inmediatez con Dios, entonces hay que dejar espacio en un análisis de la realidad para que ese profetismo se manifieste. La mirada profética es casi siempre una mirada extraña para la mayoría, incomprendida y, por eso, muchas veces rechazada. Soledad y ministerio profético son dos realidades que conviven a menudo. De este modo, sería necesario dejar espacio para que se manifieste la novedad y la sorpresa de las experiencias individuales, evitando eliminarlas, por ejemplo, en las búsquedas apresuradas de consensos.

El ser humano singular será relevante en todo el proceso de la teología práctica, no solo en el análisis de la situación presente. Las intuiciones individuales serán importantes en el discernimiento de los imperativos concretos, en el diseño de una estrategia y, de modo particular, en la realización concreta de tales imperativos. En ese sentido es relevante el planteamiento de Rahner de que, en última instancia, la Iglesia alcanza la vida concreta solo en la acción de los seres humanos singulares: «la realización de sí misma, necesaria y obligante, para la Iglesia [realización] que siempre tiene también una contingencia histórica concreta, es de hecho solo posible a través de la libre decisión y la libre acción de cristianos individuales, sin que la Iglesia, a partir de sí misma, pueda obligar en sentido estricto a individuos determinados a esto, en el modo de una ley o de una orden concreta, a cuya observancia podría forzar $»^{31}$. H. Vorgrimler subraya la importancia dada por Rahner al individuo en la autorrealización de la Iglesia:

30 Cf. M. Schneider, "L'orizzonte della spiritualità ignaziana della teologia di Karl Rahner» en I. SANnA, L'eredità teológica di Karl Rahner, 31-47, 32. 45.

31 K. Rahner, Zur theologischen Problematik einer, Pastoralkonstitution (Schriften zur Theologie VIII; Benziger, Einsiedeln 1967) 615-656, 622. 
«Junto a toda la marca eclesiológica de sus impulsos teológico-prácticos, no se puede olvidar que, para él el cuidado pastoral de los individuos tenía prioridad: en primer lugar estaba la 'mistagogía', la introducción de cada ser humano a la percepción de su experiencia inmediata de Dios, no de forma esotérica-elitista, sino en cada situación cotidiana. De esta situación resultaba, pasando por la experiencia concreta de Jesús, la decisión personal singularísima en cada caso, por la fe en la revelación de Dios. A eso pertenecía también el estímulo para permitir que se tornasen efectivos los carismas personales en cada momento y para sondear la voluntad de Dios para la propia existencia en cada momento ${ }^{32}$. Esto no significa dejar de lado la experiencia comunitaria y eclesial, sino que impone el desafío de una experiencia comunitaria y eclesial, como contexto de una teología práctica, que le dé relevancia a las experiencias individuales, promoviéndolas y alimentándose de ellas. En esta perspectiva lo individual y lo colectivo crecen en la misma medida, es decir, la mayor individualización es lo que asegura una mayor socialización. Por ello Rahner llama a promover la célula [Zelle], la pequeña comunidad, como punto de encuentro entre individualidad y sociedad ${ }^{33}$.

Por otro lado, la relevancia del ser humano singular debiera manifestarse también en la referencia de la teología práctica al dato revelado:

a) En la referencia a Jesucristo adquieren relevancia no solo los valores del Evangelio, el contenido de su mensaje, sino la persona misma de Jesús. Parece ser esa la intuición de Ignacio que invita en sus Ejercicios, no solo a confrontarse con un proyecto (una bandera), sino con la propia persona de Jesús. Para M. Schneider, en los Ejercicios la vida concreta de Jesús, o sea, su cotidianeidad, se revela como el criterio definitivo y objetivo de la búsqueda de la forma concreta del propio seguimiento. Su vida concreta no es solo un ejemplo paradigmático de una vida humana feliz, ni un ideal abstracto, ni un ejemplo de vida exitosa; ella representa mucho más «la unicidad concreta e indisoluble en el sumo cumplimiento, 'l'absolutum concretissimum'»'34. Así, Schwerdtfe-

32 H. Vorgrimler, Karl Rahner. Gotteserfahrung in Leben und Denke (Wissenschaftliche Buchgesellschaft Darmstadt 2004) 78.

33 Cf. K. Rahner, Über die heilsgeschichtliche Bedeutung des einzelnen in der Kirche, 445- 446.

34 M. SchneIder, «L'orizzonte della spiritualità ignaziana della teologia di Karl Rahner» 39. [Cursivas del autor] 
ger piensa que en Rahner esto significa que el estudio de las diversas fases de la vida de Jesús no puede considerarse solamente una reflexión de tipo moral, pues se instaura una relación real y no solo abstracta con la vida de Jesús, relación que transmite la gracia para el seguimiento ${ }^{35}$. En esta línea también nos parece que se coloca la exhortación de la $\mathrm{V}$ Conferencia de Aparecida: «A todos nos toca recomenzar desde Cristo, reconociendo que no se comienza a ser cristiano por una decisión ética o una gran idea, sino por el encuentro con un acontecimiento, con una Persona que da un nuevo horizonte a la vida y, con ello, una orientación decisiva ${ }^{36}$.

b) En la referencia a las Sagradas Escrituras adquieren relevancia las situaciones particulares (en cuanto magnitudes individuales) del pueblo de Israel y de las primeras comunidades cristianas en cada momento histórico, de modo especial la nube de testigos que forman parte de esa historia.

Además del dato revelado consignado en las Escrituras, que tendría el estatus de criterio principal, es posible pensar en otras fuentes de normatividad, por ejemplo, la vida de los santos. Schneider plantea la necesidad de introducir en la reflexión teológica la realización de la vida cristiana tal como es representada por los santos, por cuanto ellos son creadores de un nuevo estilo cristiano ${ }^{37}$. La experiencia de Dios que hacen los santos tiene una importancia normativa para la vida de la Iglesia, llegando a adquirir esta autoridad de los santos un significado gnoseológico para la teología ${ }^{38}$. Como lo afirma Melchor Cano, la autoridad de los santos es un locus theologicus y el sentir de todos los santos es el sentir del mismo Espíritu ${ }^{39}$. Por

35 Cf. N. Schwerdtfeger, Betrachtungen zum ignatianischen Exerzitienbuch, 163, apud M. SchNeIDER, «L'orizzonte della spiritualità ignaziana della teologia di Karl Rahner», 39.

Episcopado latinoamericano y del Caribe, Documento conclusivo. V Conferencia General de Aparecida. (CECH, Santiago 2007) no 12.

37 Cf. K. Schneider, «L'orizzonte della spiritualità ignaziana della teologia di Karl Rahner», 35.

38 Cf. W. Beinert, «Die Heiligen in der Reflexion der Kirche» en: Id., (ed.) Die heiligen heute ehren (Herder, Freiburg 1983) 61, apud M. SCHNEIDER, «L'orizzonte della spiritualità ignaziana della teologia di Karl Rahner», 44.

39 M. CANO, «De locis theologicis liber VII de sanctorum auctoritate» en: Id., Opera, II. (Forzani, Roma 1890)63, apud M. SchneIder, «L'orizzonte della spiritualità ignaziana della teologia di Karl Rahner», 44. 
su parte V. Balthasar afirma que «el comentario más auténtico de la Palabra de Dios hecha carne son, en primer lugar, los santos» ${ }^{40}$. Así también se afirma en el Vaticano II que el sensus fidei de todo el Pueblo de Dios encuentra en los santos su expresión auténtica (LG 12, DV 8).

\subsubsection{Las experiencias de sufrimiento}

Tenemos la impresión que otro camino para mirar el presente desde la futuridad del presente es prestar atención al sufrimiento humano y, a partir del desafío de una forma biográfica de la teología práctica, prestar atención no al sufrimiento en abstracto, sino a los sufrientes concretos, a las víctimas, a los pobres, a los insignificantes. En la conversión a los dolientes no encontramos un sentido, sino la apertura permanente a un futuro. La conversión al dolor humano nos pone en tensión escatológica permanente, a partir de lo que podríamos llamar «nostalgia del futuro». Nostalgia, pues la plenitud anhelada de cara a la realidad de los sufrientes es ya una realidad presente, por cuanto Dios se ha autocomunicado y en Jesucristo se ha revelado como el futuro absoluto de la historia, futuro de plenitud especialmente para los pobres, los que tienen hambre, los que lloran (cf, Lc 6, 20-21). De cara a esa condición de caminar en la meta el dolor de los sufrientes se hace más escandaloso, pues el dolor humano no es el camino necesario para la selección natural (evolucionismo) o la inmolación necesaria de la generación actual en pro de las generaciones futuras (marxismo). Pero es nostalgia del futuro, pues la anamnesis de lo que ha sucedido en Cristo nos abre a un hambre y sed de plenitud, para que se manifieste aquello que ya somos. Se trata de una nostalgia no de cualquier futuro, sino del futuro absoluto, es decir, un futuro cuya realización plena no es histórica, sino que trasciende una y otra vez las utopías intramundanas y tiene como fin último a Dios mismo. Esta nostalgia del futuro posibilita el desapego en relación con las realizaciones intramundanas, no porque sean poco importantes, sino porque son trascendidas una y otra vez por el anhelo o, mejor, por la atracción del futuro absoluto. La conversión a los sufrientes nos pone delante del fracaso constante de los esfuerzos intramundanos, no porque en ellos no se logre nada, sino por la desproporción entre el logro y lo deseado: Dios mismo.

40 U. Von Balthasar, "Geist und Feuer. Ein Gespräch mit Hans Urs von Balthasar» en Herder Korrespondenz 30 (1976)72-82, 75. 
A partir de la perspectiva escatológica que hemos estudiado, se trata de una conversión a los sufrientes «en el modo de la plenitud», es decir, una conversión que no paraliza ni hace caer en el desánimo, que no ancla en la pura oscuridad y el pesimismo, sino que compromete en la tarea intramundana por un mundo más justo. La superación de tal oscuridad y pesimismo no se da porque logremos vislumbrar la claridad de un sentido, sino solo en la esperanza de que toda la existencia ha sido redimida en la cruz de Cristo.

De este modo la conversión a los sufrientes será relevante en un análisis de la situación presente, pues posibilitará tomar distancia de miradas triunfalistas, autoafirmadoras de la praxis existente, poniéndonos siempre de cara a una mayor plenitud, tornándose fuente de un potencial crítico permanente. A partir de ahí cobrará importancia esa conversión a los sufrientes para el discernimiento de los imperativos concretos, pues los sufrientes no son solo un medio para analizar la realidad, sino que tal conversión llevará a pensar los caminos de una praxis eclesial que colabore a que el sufrimiento sea aliviado para que todos tengan vida y vida en abundancia. Porque se trata de todos y no solo de los miembros de la Iglesia, es una meta que solo puede ser alcanzada asintóticamente.

La posibilidad de mirada crítica implica libertad y la libertad supone indiferencia. La conversión a los sufrientes en la comunión con la cruz de Cristo es un camino para la indiferencia que propone Ignacio, que no permite considerar como final una realización mundana concreta. Esta conversión a los sufrientes no puede ser solo una conversión intelectual, una mirada a distancia, sino que es invitación al con-sufrir el dolor de las víctimas, en la convicción de que ese con-sufrir es fundamental para conocer en profundidad. Parece ser esta una exigencia del conocimiento estrechamente vinculado al amor. De este modo, el desafío de la teología práctica no es solo -como lo plantea Rahner-salir de la universidad para alcanzar la praxis concreta de la Iglesia, sino más todavía, ella debe llegar allí donde están los sufrientes.

\subsection{Conocer desde los otros}

Intentando (esbozar apenas) una lectura de Rahner desde Lévinas se podría decir: Si todo ser humano es individuum ineffabile entonces todo otro es siempre misterioso, inasible, imposible de ser reducido a conceptos. El otro, lo otro, es importante en el planteamiento de Rahner, pues 
el ser humano solo puede ser presencia a sí en el alejarse de sí para ser presencia a otro y en el retorno a sí desde el otro. Solo desde lo otro y desde el otro puede encontrarse a sí mismo, en un movimiento que nunca termina. Lo mismo acontece con la Iglesia que -en el planteamiento de Rahner- llega a sí misma siempre desde lo otro de sí. En ese sentido el otro es mesías del sujeto, porque no lo deja autocentrarse, porque quiebra su síntesis propia y lo mantiene siempre abierto al misterio, podríamos decir, porque lo mantiene siempre en tensión escatológica. El otro quiebra siempre la intencionalidad del sujeto porque él se significa a sí mismo en el lenguaje ${ }^{41}$. Por ello hay contenido en el otro un inagotable potencial crítico. El otro es epifánico, pues en él se revela el misterio, pero siempre escapándose y mostrando apenas las espaldas. El otro invita al sujeto a la responsabilidad, por cuanto en la desnudez de su rostro le dice: «cuida de mí»»2.

En un análisis de la situación presente hay que evitar miradas demasiado autorreferentes que no presten atención a lo que ocurre fuera de la Iglesia. De hecho el análisis de la situación tiene como objeto la situación presente de la Iglesia y del mundo. La mirada que los otros tienen de la Iglesia puede ser de gran provecho, al aportar otros criterios, otros ángulos de mirada que ayudarán a una mayor lucidez del análisis. Incluso en la búsqueda de criterios que ayuden al discernimiento de los imperativos concretos, serán relevantes aquellas experiencias de plenitud profanas, pues toda vida humana tiene una dimensión de revelación por cuanto está siempre sustentada por la autocomunicación de Dios. Esas experiencias de plenitud que están más allá del ámbito de la Iglesia, leídas siempre a la luz del dato revelado y, particularmente, desde Jesucristo, pueden ser también horizonte crítico e inspirador.

También serán relevantes las experiencias de no plenitud, de sufrimiento. Las necesidades de los otros son importantes en el diseño de una estrategia eclesial, así como lo fueron en la praxis de Jesús, que se desviaba del camino, interrumpía su itinerario a partir de las necesidades de quienes encontraba en el camino. La experiencia del otro debe ser leída teológicamente como llamado de Dios, en una situación histórica concreta, para la conversión de la Iglesia hacia una mayor plenitud. En

41 Cf. E. LÉvinas, «La conscience non-intentionnelle» en: Id., Entre nous. Essais sur le penser-à-l'autre (Bernard Grasset, París 1991) 150-151.

42 Cf. E. LÉvinas, «Philosophie, Justice et Amour» en: Id., Entre nous, 121-123. 
ese sentido se puede afirmar que el mundo tiene una dimensión salvífica para la Iglesia. Esto supone el desafío de la convivencia y el diálogo, la aproximación al diferente, liberando a la Iglesia de la tentación de comprenderse a sí misma como ghetto.

En ese sentido cobra una especial importancia la mirada de las otras ciencias humanas, en cuanto modos diferentes de aproximación a la realidad, complementarios a la aproximación propiamente teológica. Entonces, no se trata solo de una asunción teológica de la mirada de las ciencias humanas en un segundo momento de reflexión, sino una mirada de esas ciencias que entra en diálogo con la mirada propia de la teología.

\subsection{La narratividad}

La narratividad es una dimensión fuertemente presente en la dinámica de los Ejercicios Ignacianos. El maestro de Ejercicios debe poner la narración del ejercitante delante de la narración de la vida de Jesús. En ese encuentro de experiencias contenidas en ambas narraciones se hace una experiencia auténtica de Dios que adquiere forma de un llamado totalmente personal y único. La narratividad aparece como un modo de aproximación a la realidad que respeta el carácter único e indeducible de la experiencia individual. Si la praxis tiene una inteligibilidad propia fundada en la singularidad de las acciones libres de los seres humanos, entonces, encontramos en la narratividad un camino de acceso a una praxis así concebida. De algún modo la narratividad preserva mejor la singularidad y originalidad de la experiencia vivida. Esto se conecta bien con el desafío de una teología práctica de carácter biográfico que señalamos más arriba. El desafío será, entonces, la integración de narratividad y conceptualización.

En un ejercicio de discernimiento de los imperativos concretos se podría poner frente a frente la narratividad de la vida del individuo o comunidad y la narratividad del proyecto de Dios contenido en la Sagrada Escritura, de modo particular, delante de la vida de Jesucristo, para dejar que Dios llame, interpele, revele su llamado en una determinada situación presente. La vida de los santos puede ser otro referente narrativo. Este encuentro de narraciones buscaría evitar que el círculo se cierre demasiado en la búsqueda de síntesis, consensos, incluso censuras apresuradas. De este modo la narratividad de la vida de cada uno y de 
la comunidad es leída y asumida «en el modo de la plenificación». La narratividad puede ser, entonces, un modo formal del proceso global de una teología práctica.

\subsection{La corporeidad}

Uno de los desafíos más importantes para un análisis de la situación presente es tomar distancia de miradas idealistas, de aproximaciones cargadas de prejuicios y posturas ideológicas, para intentar acceder a una mirada más fidedigna de la realidad. Tenemos la impresión de que la corporeidad puede ser una clave en ese sentido, pues el cuerpo es una especie de sentido de realidad que conecta al ser humano a cada momento con un aquí y ahora concreto. Esto se vincula al planteamiento de Rahner de Geist in Welt, a saber, el espíritu finito conoce por un doble dinamismo: sensibilidad como praesentia mundi y pensamiento como oppositio mundi y, por eso, el ser humano solo puede ser en el mundo en la conversio ad phantasma ${ }^{43}$.

La importancia dada a la corporeidad parece ser una intuición de san Ignacio, que se manifiesta en la invitación a hacer en los Ejercicios un camino siempre conectado con la sensibilidad, por ejemplo, en la aplicación de los sentidos, en la meditación de la vida de Jesús a través de la imaginación ${ }^{44}$, en la experiencia de consolación y desolación que permanecen conectadas a una dimensión sensible. De alguna manera se busca en los Ejercicios quebrar un modo de situarse delante de Dios demasiado intelectual, abstracto y, por eso, autocontrolado. Prestar atención a la sensibilidad, dejando que se exprese la espontaneidad del cuerpo, es un camino hacia una mayor proximidad con la realidad personal que dispone de modo más experiencial al encuentro con Dios.

El desafío es, entonces, integrar en el análisis de la situación presente esa dimensión de la corporeidad que, además, permitiría una aproxima-

43 El segundo capítulo de la segunda parte de Geist in Welt está dedicado a la praesentia mundi, a través del tema de la sensibilidad, y en el capítulo tercero de la segunda parte Rahner trabaja la opositio mundi, a través del tema del pensamiento.

44 P. ej. en la meditación del infierno en la que invita a hacer una experiencia del ponerse del lado de los condenados, a través del ver, oír, oler, gustar y tocar (Cf. EE.EE. 65-70). También en la composición de lugar y la aplicación de los sentidos en las meditaciones de los misterios de la vida de Jesús, cf. p. ej. la contemplación del nacimiento (EE.EE., 110-116). 
ción a la singularidad de la experiencia de los individuos, en el contexto de una teología práctica biográfica; es el desafío de un análisis de la situación presente que sepa leer la narratividad del cuerpo. Esta puede ser una clave también a la hora del discernimiento comunitario de espíritus para la toma de decisiones concretas, pues siempre en la base de una acción existe (o debe existir) una emoción.

Especialmente importantes son los imaginarios de futuro de las personas y los grupos humanos como reveladores de un horizonte de plenitud; por ello deben ser acogidos y siempre purificados, en la línea de lo que plantea Hünermann ${ }^{45}$, que cree que una afirmación escatológica puede provenir también desde afuera, desde las representaciones del más allá y desde ahí preguntar de vuelta por el ser humano como sujeto escatológico.

\subsection{Indiferencia: situarse desde la incondicionalidad}

Los Ejercicios Ignacianos, en la medida que son un discernimiento para una decisión, tienen como propósito ayudar al ejercitante a situarse ante la elección desde la mayor libertad posible; esta recuperación de su libertad más radical es posible si la integra en la libertad de Dios ${ }^{46}$. Aquí adquiere particular relevancia la indiferencia ignaciana, pues, para que el ejercitante pueda elegir o rechazar un objeto particular, con auténtica libertad, necesita distanciarse [Fernerücken] del apego inmediato a ese objeto para experimentar la inmediatez de Dios como el único foco de su existencia ${ }^{47}$. Este desapego, no solo teórico, sino existencial, consiste -consciente o no- en la participación-actuante [Mitvollzug] en la muerte de Cristo. La persona libre es aquella que, por gracia (la de Cristo crucificado), ha sido liberada de la esclavitud de los «principados y po-

45 Cf. P. Hünermann, Eschatologie. Gottes Ankunft - Zukunft des Menschen (WS, Tübingen 1993/1994)8. 9-12; cf. 14-65, apud C. SchickendantZ, Autotrascendencia radicalizada en extrema impotencia. La comprensión de la muerte en Karl Rahner (Pontificia Universidad Católica de Chile, Santiago 1999) 209.

46 Cf. K. Rahner, Rede des Ignatius von Loyola an einen Jesuiten von heute (Sämtliche Werke 25; Herder, Freiburg 2008) 299.

47 Cf. K. Rahner, Mystik - Weg des Glaubens zu Gott (Sämtliche Werke 29; Herder, Freiburg 2007) 58-66, 64; cf. tb. K. RaHner, Moderne Frömmigkeit und Exerzitienerfahrung (Sämtliche Werke 25; Herder, Freiburg 2008) 213-231, 218-219. 
testades de este mundo ${ }^{48}$. No solo es participación en la muerte en la cruz de Jesús, sino en su completa vida, pues en ella Jesús va muriendo poco a poco al entregarse radicalmente a la voluntad de Dios; nuestro autor la llama «vida muriente de Jesús» [sterbendes Leben Jesu]. Es una dinámica que "tiene un carácter 'cristoconformante' ${ }^{49}$.

Allí donde el ser humano ha tomado distancia radical de la realidad particular de su propia existencia y ya no se pertenece más a sí mismo, ni dispone más de sí, allí donde se desmorona la autocomprensión de sí y del mundo en una "noche del sentido y del espíritu» (particularmente en los terribles callejones sin salida [Ausweglosigkeiten] de la vida en los que tomamos conciencia de nuestra radical vulnerabilidad e impotencia), se comienza a experimentar la propia trascendentalidad del ser humano hacia $\operatorname{Dios}^{50}$; entonces se comienza a vivir en el mundo de Dios, a vivir del Dios de la gracia y de la vida eterna ${ }^{51}$.

El proceso de los Ejercicios es una invitación a la persona a ponerse en una situación de indiferencia, es decir, de libertad radical en vistas de la elección, libertad que irá profundizándose hasta el final del proceso ${ }^{52}$. Un discernimiento de imperativos concretos para la autorrealización de la Iglesia necesita de esa libertad, para que no sea una mera lucha de visiones ideológicas, o una expresión de la inercia que le teme a lo nuevo, o de un apego que pone en primer lugar la subsistencia, o de una búsqueda autocentrada. El desafío es, entonces, integrar en un proceso

48 Cf. K. Rahner, Comments by Karl Rahner on Questions raised by Avery Dulles (Sämtliche Werke 25; Herder, Freiburg 2008) 244-247, 246; cf. K. Rahner, "Vorwort» en: Id., Ignatius von Loyola. Geistliche Übungen. Übetragung und Erklärung von Adolf Haas (Sämtliche Werke 25; Herder, Freiburg 2008) 232-233, 232 y cf. K. RAHNer, Rede des Ignatius von Loyola an einen Jesuiten von heute, 310.

49 K. Rahner, "Vorwort» en H. Egan, The Spiritual Exercises and the Ignatian mystical horizon (Sämtliche Werke 25; Herder, Freiburg 2008) 236-242, 241.

Cf. K. Rahner, Mystik -Weg des Glaubens zu Gott, 64; cf. tb. K. Rahner, Rede des Ignatius von Loyola an einen Jesuiten von heute, 304.

51 Cf. K. Rahner, Erfahrung des Heiligen Geistes (Sämtliche Werke 29; Herder, Freiburg 2007) 38-57, 52.

52 Esta libertad se expresa magníficamente en la oración de la contemplación para alcanzar amor: "Tomad, Señor, y recibid toda mi libertad, mi memoria, mi entendimiento, y toda mi voluntad, todo mi haber y mi poseer; vos me lo distes, a vos, Señor, lo torno; todo es vuestro, disponed a toda vuestra voluntad, dadme vuestro amor y gracia, que esta me basta». EE.EE., 234. [Adaptaciones de la grafía son nuestras] 
así un itinerario comunitario hacia esa libertad, que coloque los fundamentos para un discernimiento auténtico: profético, abierto a lo nuevo, dispuesto al «tuciorismo del riesgo» [Tutiorismus des Wagnisses].

¿Cómo provocar un discernimiento de una comunidad en situación de indiferencia, de modo de no planificar como lo hace una empresa que no puede arriesgar sus lucros y menos su subsistencia?

\subsection{Kairología, criteriología y praxeología}

En el esfuerzo de, con Rahner, ir más allá de Rahner, nos parece interesante la estructuración de la teología pastoral que hace Zulehner, pues tenemos la impresión que explicita mejor lo que está contenido en la intuición de Rahner. Este autor divide el método de una teología pastoral en tres momentos: kairología, criteriología y praxeología ${ }^{53}$.

- Kairología: Nos parece relevante lo que aporta el concepto kairología al análisis de la situación presente, pues no se trata solo de analizar una situación histórica, sino un kairós, una situación presente al interior de una historia de salvación. Creemos que ese concepto pone de relieve de modo más directo la cualidad teológica de tal análisis y abre a otras posibilidades de mirada, pues esta kairología puede ser realizada a través de una aproximación no solo científico-sistemática, sino también sapiencial. En una kairología queda más claro que las ciencias humanas son ciencias auxiliares.

- Criteriología: la criteriología permitirá hacer el ejercicio del discernimiento de los imperativos en el modo de la plenitud, definir el horizonte de referencia, el hacia dónde, que expresa en cada situación concreta la voluntad de Dios para la Iglesia. Kairología y criteriología deben estar en permanente diálogo, pues la criteriología no es un referente estático, sino que se va revelando en sus posibilidades de modo siempre nuevo, a partir de cada kairós. A su vez, la criteriología también será relevante para saber cómo aproximarse a la realidad presente, justamente, para percibirla como un kairós.

- Praxeología: una teología práctica puede iluminar el modo como los imperativos concretos son llevados a la vida de forma que no se transformen de nuevo en prácticas anquilosadas porque ya no responden

53 Cf. P. Zulehner, Pastoraltheologie I. Fundamentalpastoral: Kirche zwischen Auftrag und Erwartung (Patmos, Düsseldorf 1989) 15. 
a una nueva situación histórica. Tiene que ver, por ejemplo, con lo que Rahner caracteriza como una dejar más libre al cristiano para que pueda actuar con mayor autonomía, así como con la necesidad de una actitud autocrítica permanente. También se sitúa en este nivel la posibilidad planteada por Rahner de que la lógica de la decisión existencial sea realizada por pequeñas comunidades. Praxeología, kairología y criteriología están siempre en interrelación, cada una con la otra y las tres en conjunto.

Estas mediaciones presentadas podrían servir de base para el diseño de un método con una secuencia de pasos bien definidos y articulados, a partir, por ejemplo, de la estructuración en los tres momentos propuestos por Zulehner. Un diseño detallado de tal método es, sin duda, un buen estímulo para seguir investigando. 
Resumen: A partir de una comprensión de la teología práctica de Karl Rahner como una teología pastoral en perspectiva escatológica, y teniendo como plano de fondo el problema del carácter teológico del análisis de la situación presente, presentamos algunas posibles mediaciones para un método de teología pastoral, a saber, mirar el futuro desde la "futuridad del presente", conocer desde los otros, la narratividad, la corporeidad y la "indiferencia".

Palabras clave: Rahner, teología pastoral, teología práctica, método, escatología, individuum ineffabile, kairología, narratividad.

Abstract: Based on understanding of Karl Rahner's practical theology as a pastoral theology in an eschatological perspective, and having as a background the theological problem of analyzing the present situation, we present some possible mediations for a pastoral theology method, namely, looking at the future from a "futurity of the present," knowing from others, narrative, corporeality and "indifference." Keywords: Rahner, pastoral theology, practical theology, method, eschatology, individuum ineffabile, kairology, narrative. 